\title{
Intervention of Dynapod in Cleaner-cum-Grader for Drudgery Reduction
}

\author{
R R POTDAR, P S TIWARI, K N AGRAWAL, BIKRAM JYOTI* AND PRABHAKAR SHUKLA
}

\begin{abstract}
An ergonomic evaluation cleaner-cum-grader with original cycle mechanism and ICAR-CIAE developed dynapod was conducted. The study was conducted with 15 male subjects aged between $20-40$ years, mean stature of $1640 \pm 40 \mathrm{~mm}$ and mean weight of $54 \pm 5 \mathrm{~kg}$. The maximum aerobic capacities of the subjects were determined using sub-maximal exercise protocol. Themean working heart rate of the subjects in operation of machine with original cycle mechanism was 157 beats $\min ^{-1}$ as against 125 beats min $^{-1}$ with dynapod. The work pulse $(\Delta H R)$ of 57 beats $\min ^{-1}$ and 31 beats $\min ^{-1}$ was observed for pedaling with cycle mechanism and dynapod, respectively. The output capacity of machine increased by $41 \mathrm{~kg} \mathrm{~h}^{-1}$ with use of dynapod compared to pedaling with cycle mechanism. Using dynapod in operation of cleanercum-grader resulted in drudgery reduction by $51.6 \%$ as compared to the original cycle mechanism.
\end{abstract}

\section{KEYWORDS}

Cleaner-cum-grader; Dynapod; Cycle mechanism; Heart rate; Work pulse; Drudgery reduction

\begin{tabular}{lll}
\multicolumn{2}{c}{ ARTICLE INFO } \\
\hline Received on & $:$ & $21 / 11 / 2020$ \\
Accepted on & $:$ & $21 / 02 / 2021$ \\
Published online & $:$ & $19 / 03 / 2021$ \\
\hline
\end{tabular}

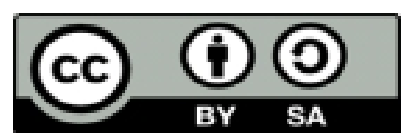

\section{INTRODUCTION}

$\mathrm{I}$ $\mathrm{n}$ manual agricultural activities, the energy is generally applied through hands/arms. Many of the agricultural operations as sowing, weeding, pesticide application, harvesting, transportation, fodder cutting, material handling and post harvest operations on Indian farms are performed with manual farm tools and equipment. Many manually operated farm equipment need rotational power to be provided by operator either by upper or lower limbs or combination of both. With the development of bicycle during industrial revolution, humans started using legs for generation of rotary power by applying muscular force. It has been established through biomedical research that the more power is produced with lower fatigue by pedalling than by hand cranking. The cycle mode was found to be less strenuous and least energy demanding in terms of physiological and postural parameters. Also, for rotary power generation it was efficient (up to $60 \mathrm{~W}$ load) in comparison to hand cranking, hand rocking lever, foot pedal and dual foot pedal (Potdar et al., 2011).

Several researchers around the globe has studied and reported the role of ergonomics in designing bicycle for transport, sports and rehabilitation activities (Seabury et al., 1977; Coast et al., 1986; Marsh and Martin, 1993 and1997; Neptune and Hull, 1999; Marsh et al., 2000). Moreover, very little work has been reported related to application of pedal power for farm operations in static and stationary conditions.

Most of manually operated stationary machines are operated either in cranking or in reciprocating mode by hands or legs. However, both these power application modes using human

ICAR-Central Institute of Agricultural Engineering, Nabibagh, Bhopal, India *Corresponding author email : bikram.santwana@gmail.com muscles are inefficient and cause more fatigue to the operator. The dynapod can be efficiently used to enhance the overall productivity of these machines with reduction in drudgery.The dynapod developed at ICAR CIAE increased the output capacity of rotary maize sheller by use of ergonomically developed dynapod from $144.42 \mathrm{~kg} \mathrm{~h}^{-1}$ (cranking through hand) to $282.7 \mathrm{~kg} \mathrm{~h}^{-1}$ and reduced work pulse from 59.4 to 35 beats $\mathrm{min}$ ${ }^{1}$ (Tiwari, 2012). To increase the versatility of dynapod, it was interfaced with CIAE design pedal operated cleaner-cumgrader. Therefore, a study was conducted for efficiently utilizing the human power by interfacing dynapod with cleaner-cum-grader.

\section{MATERIALS AND METHODS}

\section{Pedal-operated cleaner-cum-grader}

The pedal operated cleaner-cum-grader (Fig. 1) is used for cleaning and grading the threshed grain containing light chaff materials, stones and soil particles. The cleaner-cum-grader

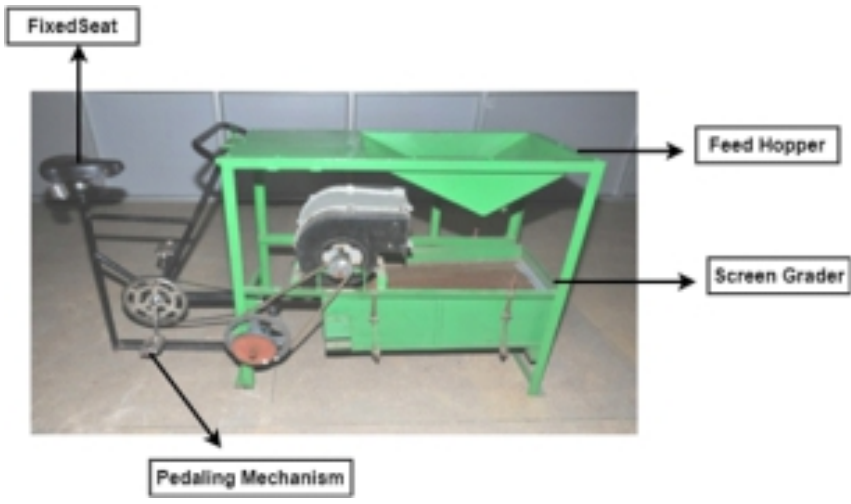

Fig. 1 Pedal operated cleaner-cum-grader 
with output capacity of about $300-350 \mathrm{~kg} \mathrm{~h}^{-1}$ consists of a hopper having capacity of $25 \mathrm{~kg}$ of grains, a blower, a set of sieves and a cycle pedalling mechanism. The overall dimension of the machine is $1600 \times 500 \times 1000 \mathrm{~mm}$ and weight $110 \mathrm{~kg}$. The power to the blower and sieves is transmitted from cycle mechanism through the arrangement of belt and set of pulleys.

\section{Dynapod}

A dynapod (Fig. 2) is a pedalling device that may be used as an interface between a human worker and any rotary machine for utilization of human muscle power in efficient manner. It was designed by Tiwari et al.(2011) and optimized to operate at $50 \mathrm{rev} / \mathrm{min}$ for sustainable work. It consists of an enclosed flywheel of diameter $520 \mathrm{~mm}$ and weight of $23 \mathrm{~kg}$.

Overall dimension of the dynapod is $1175 \times 503 \times 1100 \mathrm{~mm}$. The total weight of dynapod is $68 \mathrm{~kg}$.For Indian agricultural workers, the muscular power output in pedalling mode sustained for long duration is $60 \mathrm{~W}$. At this power output, the optimum pedalling rate, at which the physiological and psychophysical responses were minimum, is $50 \mathrm{rev} / \mathrm{min}$ (Tiwari et al., 2011, Potdar et al., 2011).

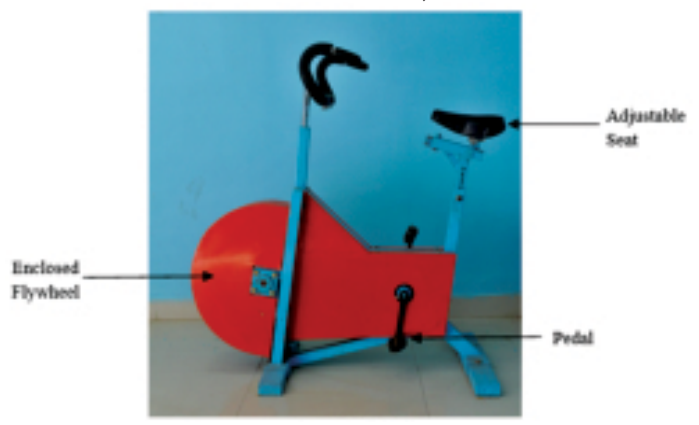

Fig. 2 Dynapod

Interfacing dynapod with cleaner-cum-grader

To get the desired cleaning efficiency and grading of the grains, the cleaner-cum-grader has to operate at the pedalling rate of $72 \mathrm{rev} / \mathrm{min}$, when the original cycle mechanism is used. At this pedalling rate, the speed of eccentric shaft and blower shaft of cleaner-cum-grader were $240 \mathrm{rev} / \mathrm{min}$ and 720 $\mathrm{rev} / \mathrm{min}$, respectively. The speed of output shaft of dynapod was about $167 \mathrm{rev} / \mathrm{min}$ at the recommended pedalling rate of $50 \mathrm{rev} / \mathrm{min}$. In order to get desired operating speeds at eccentric shaft and blower shaft of cleaner-cum-grader as mentioned above, a $254 \mathrm{~mm}$ pulley was fixed on output shaft of dynapod and $150 \mathrm{~mm}$ pulley on input shaft of cleaner-cumgrader to achieve the same performance of the machine. With these modifications, the dynapod was successfully interfaced with cleaner-cum-grader. After interfacing the dynapod with cleaner-cum-grader, the speed of eccentric shaft and blower shaft were $282 \mathrm{rev} / \mathrm{min}$ and $846 \mathrm{rev} / \mathrm{min}$, respectively at the pedaling rate of $50 \mathrm{rev} / \mathrm{min}$.

\section{Selections of subjects}

Fifteen male subjects were selected for ergonomic evaluation of cleaner-cum-grader using dynapod as well as cycle mechanism. It was ensured that the subjects selected were medically fit with no history of acute or chronic illness or cardio vascular diseases. These subjects selected from the workers who carry out different agricultural activities at the ICAR-CIAE farm. The subjects were very well acquainted with bicycle riding.

\section{Measurement of physical and physiological characteristics of subjects}

The age, weight, stature, maximum heart rate and maximum aerobic capacity of the selected subjects were measured in the laboratory. The body weight of the subjects was measured using digital weighing balance of $100 \mathrm{~kg}$ capacity $(0.1 \mathrm{~kg}$ resolution).

The stature was measured using Harpenden stadiometer with measuring range of 810-2060 mm (least count $1 \mathrm{~mm}$ ). Body mass index of the subjects were determined using the following formula (Eq.1):

Body mass index (BMI), $\mathrm{kg} \mathrm{m}^{-2}=$ Weight $(\mathrm{kg}) /$

Stature $^{2}(\mathrm{~m})$

The maximum heart rate of the subjects was determined using the equation (Eq.2) as given by Maritz et al.(1961).

Maximum heart rate, beats $\min ^{-1}=220-$ Age, years

The maximum aerobic capacity $\left(\mathrm{VO}_{2} \mathrm{max}\right)$ is the upper limit of the oxygen consumption that one can inhale and measured in $1 \mathrm{~min}^{-1}$. The $\mathrm{VO}_{2}$ maxof the selected subjects was determined in the laboratory in a controlled environment following Naughton exercise protocol on a computerized treadmill (Jaeger, Model: LE 200CE). During the exercise, the dry bulb temperature in the laboratory varied from 23 to $27^{\circ} \mathrm{C}$ and relative humidity varied from 50 to $60 \%$. The subjects were trained to perform exercise on treadmill. Also, they were instructed to have light breakfast $2 \mathrm{~h}$ prior to report in the laboratory. Each subject was given warm up exercise on the treadmill for duration of $10 \mathrm{~min}$ and asked to take rest for 30 min, so that his heart rate reached to resting level. The oxygen consumed by the subject and corresponding heart rate during the exercise on treadmill was measured using a metabolic measurement system, COSMED $\mathrm{K}_{4} \mathrm{~b}_{2}$ (Italy) and Polar heart rate monitor. After rest, the subject was asked to perform exercise by fastening Polar chest belt and face mask with other accessories. During the exercise, the data of oxygen consumption and corresponding heart rate was recorded. A linear regression between the oxygen consumption and heart rate was obtained for each individual subject. By using the linear regression equation and maximum heart rate values, the $\mathrm{VO}_{2}$ max for each selected subject was determined.

\section{Laboratory experiments}

For collecting ergonomical and mechanical performance data the cleaner-cum-grader was operated with cycle mechanism and with dynapod. The sample grain, which was used during the experiment had $3.33 \%$ of total foreign material of which $2 \%$ was chaff, $1.33 \%$ was soil and stones. Based on the sample grain mixture, upper and lower sieves were selected for grading. Some adjustments, such as slopes of sieves, slit opening, stroke length in the cleaner-cum-grader were done prior to conducting the actual experiments. The experiments 
were conducted in the ambient conditions such as 23 to $27^{\circ} \mathrm{C}$ dry bulb temperature and $50-60 \%$ relative humidity. To maintain the pedalling rate, a sound and light metronome was used that gives beep and light flash at desired rate. During the experiment with cycle mechanism, the metronome was set at the rate of 72 beeps $\min ^{-1}$ and with dynapod mode it was set at 50 beeps $\min ^{-1}$ for getting desired speeds of eccentric shaft and blower shaft and better machine performance. Prior to experiments, all the subjects were informed and given training to maintain the desired pedalling rate to match with the metronome beep and operate the machine properly. The subjects were asked to wear chest belt of polar heart rate monitor and instructed to operate the machine at the rate at which metronome was set. Before starting the experiment, the subjects were given rest of $5 \mathrm{~min}$ and corresponding resting heart rate was recorded. The trial duration of machine operation for each subject was 20 min for both the methods. The working heart rate was taken as average of last 15 min of heart rate data during operation of the machine. During experiments, the observations such as speed of eccentric and blower shaft, foreign material at different outlets, and clean grain at main grain outlet were recorded.

\section{Quantification of machine performance parameters}

The comparative evaluation of the machine operating with cycle mechanism and with dynapod, was carried out based on the performance parameters viz. output capacity and cleaning efficiency. The output capacity for every experiment with each subject was recorded. The cleaning efficiency was also determined, as it is the percentage clean grain in the total grain obtained from the grain outlet.

\section{Quantification of ergonomic parameters}

Heart rate during rest time prior to experiment were taken for calculating average resting heart rate (beats $\mathrm{min}^{-1}$ ) values. The heart rate recorded from $6^{\text {th }}$ to $20^{\text {th }}$ minute during experiment were taken for calculation of average working heart rate during work, as the physiological responses of the subjects increases at faster rate in the beginning of experiment and then stabilize after $6^{\text {th }}$ minute. For a meaningful comparison of physiological responses during operation of cleaner-cumgrader in two methods of operation, the increase in heart rate over resting heart rate $\left(\Delta H R\right.$, beats $\left.\min ^{-1}\right)$ during the experiments were calculated by subtracting resting heart rate from the working heart rate of the subjects (Gite et al., 2013 and 2020).

The linear regression relationships of $\mathrm{HR}$ and OCR developed for each individual subject for determination of $\mathrm{VO}_{2}$ max were used for calculation of oxygen consumption $\left(\mathrm{VO}_{2}\right)$ during experiments. The mean values of working heart rate determined during the experiments were used in equation to compute the corresponding values of oxygen consumption $\left(\mathrm{VO}_{2}\right)$ of the subjects for all experiments. The energy equivalent of the one litre oxygen i.e. $20.39 \mathrm{~kJ} \mathrm{~min}^{-1}$ was used for the calculation of energy expended during the experiments with all subjects. It was calculated using following equation (Eq. 3) (Khadatkar et al., 2018a).

EER, $\mathrm{kJ} \mathrm{min}^{-1}=\mathrm{VO} 2,1 \mathrm{~min}^{-1} * 20.39$

[Eq.3]
Work output during any physical activity is better expressed in terms of percentage of maximum aerobic capacity $\left(\% \mathrm{VO}_{2} \max \right)$ of subjects. Keeping this point in view, the $\% \mathrm{VO}_{2} \max$ were calculated using the following equation(Eq. 4) (Khadatkar et al., 2018b).

$\% \mathrm{VO}_{2} \max =\left(\mathrm{VO}_{2}, 1 \mathrm{~min}^{-1}\right) /\left(\mathrm{VO}_{2} \max , 1 \mathrm{~min}^{-1}\right) * 100$

The acceptable limit for energy expenditure during heavy work should be about $16.7 \mathrm{~kJ} \mathrm{~min}^{-1}\left(4 \mathrm{kcal} \mathrm{min}^{-1}\right)$. This working norm had been used as a basis for calculating necessary rest period or work rest cycles. For calculating the work rest cycles that are required during a static or dynamic physical work, an equation (Eq. 5) has been proposed by McCormic (1976).

Work rest cycles $(r), \min =\mathrm{T}(\mathrm{E}-\mathrm{a}) /(\mathrm{E}-\mathrm{b})$

Where, ' $r$ ' is the work rest cycle, min; ' $T$ ' the total working time, min; ' $E$ ' the energy expenditure during the work, $\mathrm{kJ} \mathrm{min}^{-1}$; ' $\mathrm{b}$ ' the energy expenditure during the rest, $\mathrm{kJ} \mathrm{min}^{-1}$; and ' $\mathrm{a}$ ' is the average level of energy expenditure considered acceptable, $\mathrm{kJ}$ $\min ^{-1}$. The work rest cycles were calculated for the all experiments.

The cardiac cost per unit output gives a proper index for comparison of two methods of operation of the cleaner-cumgrader and is calculated using following formula [Eq. 6]

Cardiac cost $\left(\right.$ beats $100 \mathrm{~kg}^{-1}$ grain $)=\left(\Delta \mathrm{HR}^{*} 3600\right) /$ Work output, $\mathrm{kgh}^{-1}$

[Eq. 6]

The percentage of drudgery reduction was the ratio of reduction in cardiac cost by use of dynapod to the total cardiac cost of use of original cycle mechanism. Workload evaluation techniques include classification of work severity based on published guidelines for heart rate, oxygen consumption rate and percentage of $\mathrm{VO}_{2} \max$ (Table 1). The workloads in the two methods used for the operation of cleaner-cum-grader were classified. Different studies have given oxygen consumption values as percentage of $\mathrm{Vo}_{2}$ max for sustainable working. Saha et al. (1979) have given an acceptable workload for Indian workers as the work consuming $35 \%$ of $\mathrm{VO}_{2}$ max.

\section{Data analysis}

The data on output capacity, cleaning efficiency, working heart rate, work pulse, cardiac cost, oxygen consumption, energy expenditure, \% $\mathrm{VO}_{2} \mathrm{max}$ and work rest cycles

Table 1: Categorization of workload in agricultural operations based on physiological variables

\begin{tabular}{|c|c|c|c|c|}
\hline \multirow[b]{2}{*}{$\begin{array}{l}\text { Physiological } \\
\text { workload }\end{array}$} & \multicolumn{4}{|c|}{ Physiological Variables } \\
\hline & $\begin{array}{c}\text { Heart rate } \\
\text { (beats } \min ^{-1} \text { ) }\end{array}$ & $\begin{array}{c}\mathrm{O}_{2} \\
\text { consumption } \\
\left(1 \mathrm{~min}^{-1}\right)\end{array}$ & $\begin{array}{c}\text { Energy cost } \\
\left(\mathrm{kJ} \mathrm{m^{-1 } )}\right.\end{array}$ & $\begin{array}{c}\mathrm{VO}_{2 m a x} \\
(\%)\end{array}$ \\
\hline $\begin{array}{l}\text { Sedentary/ } \\
\text { very light }\end{array}$ & Below 75 & Below 0.35 & - & - \\
\hline Light & $75-100$ & $0.35-0.70$ & Below 9.1 & Below 25 \\
\hline Moderate & $100-125$ & $0.70-1.05$ & $9.1-18.2$ & Up to 50 \\
\hline Heavy & $125-150$ & $1.05-140$ & $18.2-27.2$ & Up to 75 \\
\hline Very heavy & $150-175$ & $1.40-1.75$ & Above 27.2 & Above 75 \\
\hline $\begin{array}{l}\text { Extremely } \\
\text { heavy }\end{array}$ & Above 175 & Above 1.75 & - & - \\
\hline
\end{tabular}

Source: Gite et al.(2020) 
Table 2: Physical and physiological Characteristics of the subjects

\begin{tabular}{lc}
\hline \multicolumn{1}{c}{ Characteristics } & Mean $\pm \mathrm{SD}(\mathrm{N}=15)$ \\
\hline Age, years & $31 \pm 9$ \\
Body weight, $\mathrm{kg}$ & $54 \pm 5$ \\
Stature, $\mathrm{mm}$ & $1640 \pm 40$ \\
BMI, kg m & -2 \\
Maximum heart rate, beats $\mathrm{min}^{-1}$ & $20.28 \pm 1.98$ \\
Maximum aerobic capacity $\left(\mathrm{VO}_{2 \mathrm{max}}\right), 1 \mathrm{~min}^{-1}$ & $189 \pm 9$ \\
Body surface area $\left(\mathrm{m}^{2}\right)$ & $2.49 \pm 0.37$ \\
\hline
\end{tabular}

determined during the experiments in operation of cleaner cum grader with two methods with 15 subjects were averaged to get the mean values and were subjected to detailed statistical analysis using $\mathrm{t}$ TEST procedure in Statistical Analysis Software(SAS).

\section{RESULTS AND DISCUSSION}

Physical and physiological characteristics of the subjects

Physical and physiological characteristics of the subjects (Table 2) were analyzed by using different parameters. The mean age, weight and stature of the selected subjects were 31 years, $54 \mathrm{~kg}$ and $1640 \mathrm{~mm}$, respectively.

The mean BMI score of the subjects was $20.28 \mathrm{~kg} \mathrm{~m}^{-2}$. The persons having BMI score below 18 has presence of chronic energy deficiency (CED) problem. The BMI of all selected subjects were above 18 and no CED reported. The BMI $60 \%$ of the subjects were low weight normal and rest were normal. The mean age predicted maximum heart rate and maximum aerobic capacity $\left(\mathrm{VO}_{2} \mathrm{max}\right)$ estimated by the technique proposed by Martiz et al. (1961) were 189 beats $\mathrm{min}^{-1}$ and 2.491 $\mathrm{min}^{-1}$, respectively and the results are in close agreement with the values reported by Nag (1981).

Table 3: Performance of cleaner-cum-grader and its ergonomic evaluation ( $\mathrm{N}=15)$

\begin{tabular}{|c|c|c|c|c|}
\hline Parameter & $\begin{array}{l}\text { With cycle } \\
\text { pedaling } \\
\text { mechanism, } \\
\text { mean } \pm \text { SD }\end{array}$ & $\begin{array}{l}\text { With } \\
\text { dynapod, } \\
\text { mean } \pm S D\end{array}$ & ' $t$ ' value & p-value \\
\hline Output capacity, kg/h & $304 \pm 7$ & $343 \pm 8$ & $-18.18^{* *}$ & 0.0001 \\
\hline Cleaning efficiency, \% & $97.02 \pm 0.36$ & $97.17 \pm 0.40$ & $-0.88 \mathrm{NS}$ & 0.3925 \\
\hline $\begin{array}{l}\text { Working heart rate, } \\
\text { beats } \min ^{-1}\end{array}$ & $151 \pm 7$ & $125 \pm 7$ & $15.73^{* *}$ & 0.0001 \\
\hline $\begin{array}{l}\text { Work pulse, beats } \\
\text { min }^{-1}\end{array}$ & $57 \pm 5$ & $31 \pm 3$ & $21.46^{* *}$ & 0.0001 \\
\hline $\begin{array}{l}\text { Oxygen } \\
\text { consumption rate, } 1 \\
\text { min }^{-1}\end{array}$ & $1.77 \pm 0.17$ & $1.28 \pm 0.12$ & $11.73^{* *}$ & 0.0001 \\
\hline 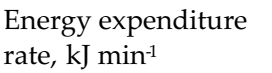 & $36.2 \pm 3.5$ & $26.1 \pm 2.4$ & $12.52^{* *}$ & 0.0001 \\
\hline $\mathrm{VO}_{2 \max }, \%$ & $72.0 \pm 6.6$ & $52.0 \pm 6.1$ & $12.94^{* *}$ & 0.0001 \\
\hline $\begin{array}{l}\text { Work rest cycles, } \\
\text { min }\end{array}$ & $10 \pm 1$ & $7 \pm 1$ & $12.16^{* *}$ & 0.0001 \\
\hline $\begin{array}{l}\text { Cardiac cost of } \\
\text { work, beats } 100 \mathrm{~kg} \\
\text { of grain }{ }^{-1}\end{array}$ & $675 \pm 54$ & $327 \pm 38$ & $23.36^{* *}$ & 0.0001 \\
\hline $\begin{array}{l}\text { Drudgery } \\
\text { reduction, \% }\end{array}$ & - & $51.3 \pm 5.8$ & - & - \\
\hline
\end{tabular}

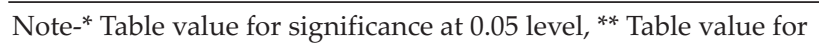
significance at 0.01 level and NS- Non significant

\section{Mechanical performance of cleaner-cum-grader}

The average blower speed increased from $722 \mathrm{rpm}$ with original pedalling mechanism to $837 \mathrm{rev} / \mathrm{min}$ during pedalling with dynapod. The output capacity of the cleanercum-grader increased significantly $(\mathrm{p}<0.01)$ from $304 \mathrm{kgh}^{-1}$ with original cycle mechanism to $343 \mathrm{kgh}^{-1}$ with dynapod (Table 3). Main reason for increase in output capacity of the machine was increased speed of eccentric shaft. It resulted in faster removal of the material from the sieves. The cleaning efficiency of the cleaner-cum-grader remained nearly same (97.02\% with original cycle mechanism and $97.2 \%$ in case of dynapod). This might be because the blower shaft speed of $722 \mathrm{rev} / \mathrm{min}$ obtained when the machine was operated with original pedalling mechanism might be sufficient for removal of chaff and other foreign material from the grain. Therefore, further increase in blower shaft speed while using dynapod had no effect on grain cleaning.

\section{Physiological responses during operation of cleaner-cum- grader}

The mean working heart rate during operation of cleanercum-grader with cycle mechanism and with dynapod were 151 and 125 beats $\min ^{-1}$, respectively (Table 3 ). The working heart rate was significantly $(\mathrm{p}<0.01)$ affected by the mode of operation. The machine operating with the dynapod yielded lower values of the working heart rate that might be due to lower pedalling rate (50 rev/min) which was optimized pedalling rate for Indian agricultural workers. In the case operating the machine with original cycle mechanism the operator had to pedal at $72 \mathrm{rev} / \mathrm{min}$ to obtain the desired speed of eccentric shaft and blower shaft to get desired machine performance and therefore, the mean working heart rate was higher.

The mean increase in heart rate over resting heart rate i.e. work pulse, $\triangle H R$, in case of pedalling with dynapod was 31 beats $\min ^{-1}$ which was significantly lower $(p<0.05)$ in comparison to that of pedalling using the cycle mechanism that yielded mean work pulse of 57 beats $\mathrm{min}^{-1}$. In former case, the mean work pulse were below 35 beats $\operatorname{~min}^{-1}$, which was an acceptable limit of work pulse for a sustainable work. The continuous rest pauses were required in case of operation with cycle mechanism as the mean work pulse was above the acceptable limit.

The mean oxygen consumption of 1.77 and $1.281 \mathrm{~min}^{-1}$ was observed in cycle mechanism mode and dynapod mode, respectively. The oxygen consumption was also significantly $(\mathrm{p}<0.01)$ affected by mode of operation and yielded lower values in case of machine operated with dynapod. As the energy expenditure is directly related to oxygen consumption, thus the mean energy expenditure too significantly $(p<0.01)$ affected by mode of operation. The machine operated with dynapod had lower mean energy expenditure rate of $26.1 \mathrm{~kJ} \mathrm{~min}^{-1}$ than that of $36.2 \mathrm{~kJ} \mathrm{m^{-1 }}$ in case of pedalling with cycle mechanism.

The percentage of $\mathrm{VO}_{2}$ max was found 72 and 52, respectively in case of pedaling with cycle mechanism and dynapod. Based on the percentage of $\mathrm{VO}_{2} \mathrm{max}$, the workload was categorized as "heavy" in case of pedaling with cycle 
mechanism, while "Moderate" in case of pedaling with dynapod. However, the percentage of $\mathrm{VO}_{2} \mathrm{max}$ in case of dynapod was on slightly higher side than the workload limit reported for moderate work. Statistically, the percentage of $\mathrm{VO}_{2}$ max also significantly $(\mathrm{p}<0.01)$ affected by the mode of operation. Based on the energy expenditure rates, the work rest cycles were computed for both the modes of operation. The work rest cycle of 10 and $7 \mathrm{~min}$ for the subjects was determined for every 20 min machine operation with cycle mechanism and with dynapod respectively. The work rest cycles were too significantly affected by the mode of operation. This means changing the mode of pedaling from cycle mechanism to dynapod significantly resulted in lowering the work rest cycle thereby enhancing the operator productivity.

The reason behind the lower physiological cost in case of dynapod might be the smoother rotary operation of the flywheel inside the dynapod. Major function of the flywheel was to store pedal energy and release this energy to maintain the uniform operation of the machine when operator stops to pedal dynapod for a moment. Due to this reason, the operator of the machine could take rest for a moment even during working and that resulted in slower down the heart rate of the operator. But this was not true in case of operating with cycle mechanism. The cycle mechanism had no flywheel to store energy, thus operators had to continuously perform pedalling to maintain the uniform operating speed of the machine. If the operator stops to pedal the cycle mechanism, the speed of various rotating parts in the machines decreases immediately due to their inertial effect. And at that moment, operator had to put more effort to increase the speed of machine to desired

\section{REFERENCES}

CoastJR, Cox RHand Welch HG. 1986.Optimal pedalling rate in prolonged bouts of cycle ergometry. Med. Sci. Sports Exerc. 18(2): 225-230.

Gite LP, Agrawal KN, Mehta CR, Potdar RR and Narawariya BS. 2020. Handbook of ergonomical design of agricultural tools, equipment and work places. Jain Brothers, New delhi.

Gite LP, Mehta CR, Tiwari PS and Potdar RR.2013. Ergonomics and Safety in Agriculture In: Handbook of Agricultural Engineering (pp 174-192). ICAR, New Delhi.

Khadatkar A, Potdar RR, Narwariya BS, Wakudkar H and Dubey UC. 2018a. An ergonomic evaluation of pedal operated paddy thresher for farm women. Indian Journal of Agricultural Sciences 88(2):280-283.

Khadatkar A, Potdar RR, Wakudkar H, Narwariya BS and Dubey UC. 2018b. Evaluation of Improved Sickle for Paddy Harvesting in Central India. Indian Journal of Extension Education 54(1):104107.

Maritz JS, Morrison JF, Peter J, Strydom NB and Wyndham CH. 1961. A practical method of estimating an individual's maximal oxygen intake. Ergonomics 4(2):97-122.

Marsh A P, Martin P E and Foley K O.2000. Effect of cadence, cycling experience and aerobic power on delta efficiency during cycling. Med. Sci. Sports Exerc. 32(9): 1630-1634.

Marsh P and Martin P E.1997.Effect of cycling experience, aerobic power and power output on preferred and most economical cycling cadences. Med. Sci. Sports Exerc. 29(9): 1225-1232. operating speed. This would put more load on the operator eventually resulting in increased physiological cost in terms of heart rate and thereby work pulse, oxygen consumption.

The mean total cardiac cost for cleaning and grading of $100 \mathrm{~kg}$ grain with original cycle mechanism and with dynapod were 675 beats and 327 beats, respectively. This showed that there was a reduction of 348 beats for cleaning and grading of $100 \mathrm{~kg}$ grain in case of pedalling with dynapod. Considering the total cardiac cost as well as output of the machine, the drudgery reduction by using dynapod with cleaner-cum-grader was $51.6 \%$ as compared to the original cycle mechanism.

\section{CONCLUSIONS}

The successful interfacing of dynapod with pedal operated cleaner-cum-grader demonstrated that a well-designed dynapod can be used to reduce drudgery involved even in pedal operated rotary machines using cycle mechanism for its operation. The output capacity of the cleaner cum grader was significantly increased by using dynapod for its operation. Also, various physiological parameters such as working heart rate, work pulse, oxygen consumption, energy expenditure and percentage of $\mathrm{VO}_{2}$ max were significantly lowered with use of dynapod in operation of machine. A 51.6\% reduction in drudgery was observed by using dynapod as compared to original cycle mechanism in operation of machine. This showed that dynapod is versatile machine that can be interfaced with any rotary type manually operated agricultural machine. The dynapod may be further tried with other rotary type manually operated machines for increasing its versatility.

Marsh P and Martin PE.1993. The association between cycling experience and preferred and most economical cadences. Med. Sci. Sports Exerc. 25(11): 1269-1274.

McCormic ET. 1976. Human Factors in Engineering and Design. Tata McGraw Hill, New Delhi.

Nag PK. 1981. Predicting maximal oxygen uptake of workers engaged in agricultural tasks. Journal of Human Ergology 10(1):25-33.

Neptune R R and Hull M L.1999.A theoretical analysis of preferred pedalling rate selection in endurance cycling. J. Biomech. 32: 409-415.

Potdar R R, Ramchandra R, Kumar A, Singh J K and Mani I. 2011. Ergonomic evaluation of rotary power input by hand and leg muscles to operate farm equipment. Journal of Agricultural Engineering 48(3):8-16.

Saha PN, Datta SR, Banerjee PK, Narayane GG.1979. An acceptable workload for Indian workers. Ergonomics 22(9):1059-71.

Seabury J J, Adams W C and Ramey M R.1977.Influence of pedalling rate and power output on energy expenditure during bicycle ergometry. Ergonomics 20(5): 491-498.

Tiwari P S.2012. Pedal power for occupational activities: Designing a dynapod. LAP LAMBERT Academic Publishing GmbH \& Co. KG. Heinrich-Bocking-Str. 6-8, 66121 Saarbrucken, Germany, ISBN: 978-3-8484-0491-9. pp 133.

Tiwari PS, Gite LP, Pandey M M and Shrivastava AK. 2011.Pedal power for occupational activities: Effect of power output and pedalling rate on physiological responses. International J. of Industrial Ergonomics 41(3): 261-267.

Citation:

Potdar RR, Tiwari PS, Agrawal KN, Jyoti B and Shukla P.2021. Intervention of dynapod in cleaner-cum-grader for drudgery reduction. Journal of AgriSearch 8(1): 35-39 